\title{
Purine Nucleoside Phosphorylase Deficiency
}

\author{
EVIDENCE FOR MOLECULAR HETEROGENEITY IN TWO
}

FAMILIES WITH ENZYME-DEFICIENT MEMBERS

\author{
William R. A. Osborne, Shi-Han Chen, Eloise R. Giblett, W. Douglas Biggar, \\ Arthur A. AmmanN, and C. Ronald Scott \\ From the Department of Pediatrics, University of Washington School of Medicine, and the King \\ County Central Blood Bank, Inc., Seattle, Washington 98195; Hospital for Sick Children, \\ Toronto, Ontario; and Department of Pediatrics, University of California, \\ San Francisco, California 94143
}

A B S T RACT Purine-nucleoside phosphorylase (NP) deficiency is associated with severely defective thymus-derived ( $\mathrm{T})$-cell and normally functioning bone marrow-derived (B)-cell immunity. In this study, two unrelated families with a total of three NP deficient members were investigated.

High pressure liquid chromatography of the plasma of the three patients showed inosine levels greater than $66 \mu \mathrm{M}$. This nucleoside was absent from the plasma of their parents and control samples.

NP was purified from normal human erythrocytes by affinity chromatography and an antiserum prepared in rabbits was used to study the NP variants in the two families.

In family $M$ the patient had no detectable erythrocyte NP activity and no detectable immunologicalreacting material (irm) to the NP antibody. The parents, who are second cousins, had less than onehalf of normal enzyme activity and approximately $14 \%$ irm attributable to a variant protein. Their electrophoretic patterns revealed a series of isozymes with slower than normal migration.

In family $B$ the patients had $0.5 \%$ residual enzyme activity and about one-half normal irm. Their electrophoretic pattern showed faintly staining bands which migrated faster than normal NP. The mother of the patients had one-half normal enzyme activity, $11 \%$ irm attributable to her variant protein, and a normal electrophoretic pattern. The father had less than one-half normal enzyme activity, equal amounts of normal and variant irm, and an electrophoretic pattern that showed in-

Received for publication 21 February 1977 and in revised form 22 April 1977. creased activity of the more rapidly migrating isozyme bands.

The combined use of immunological and electrophoretic techniques has shown the presence of three separate mutations; one in family $\mathbf{M}$ and two in family $\mathbf{B}$ associated with severely defective T-cell function.

\section{INTRODUCTION}

Purine-nucleoside phosphorylase $(\mathrm{NP})^{1}$ (EC 2.4.2.1.) catalyzes the reversible conversion of inosine, guanosine, and xanthosine to their respective free bases plus ribose-1-phosphate (1). The human enzyme appears to be controlled by a single structural gene locus on chromosome no. 14(2), and is a trimer of mol wt 84,000 $(3,4)$. Since genetic variation is rare, the three subunits are usually identical (5).

During the past $3 \mathrm{yr}$, four families have been found in which one or more members have an inherited deficiency of NP associated with severely defective thymus-derived ( $\mathrm{T}$ )-cell immunity but normal bone marrow-derived (B)-cell immunity (6-8). Specimens from two of these families were available for study in our laboratories. In family $\mathbf{M}$, the 6 -yr-old proband had no detectable NP activity in her blood cells; some clinical and metabolic studies have been reported $(6,9)$. In family $B$, the erythrocytes of the two affected male siblings (aged 9 and $11 \mathrm{yr}$ ) had about $0.5 \%$ of the normal NP activity, and their abnormal electrophoretic pattern could be demonstrated. ${ }^{2}$ In both families, the hetero-

\footnotetext{
${ }^{1}$ Abbreviations used in this paper: ADA, adenosine deaminase; EU, enzyme unit; NP, purine-nucleoside phosphorylase.

${ }^{2}$ To be published.
} 
zygous parents had half or less of the normal erythrocyte level, but the electrophoretic patterns differed.

Because these findings suggested genetic heterogeneity differentiating the NP deficient states in the two families, the studies described in this paper were undertaken.

\section{METHODS}

Blood specimens were obtained from the $M$ family in California and the B family in Toronto, Ontario. In the M family, the parents are second cousins, but no consanguinity is apparent in the B family. Venous blood collected in acid citrate dextrose solution was sent to Seattle, Wash., arriving in good condition within $48 \mathrm{~h}$. Hemolysates were prepared from washed erythrocytes (10) and the starch gel electrophoresis performed by the method of Edwards et al. (5). Hemoglobin was determined as cyanmethemoglobin (11).

NP assay. NP was assayed by the spectrophotometric method of Kalckar, monitoring uric acid formation at $293 \mathrm{~nm}$ and $37^{\circ} \mathrm{C}(12)$. A second assay system using radioisotopes was also used (13). In this method the radioactivity in hypoxanthine formed from $\left[8{ }^{-14} \mathrm{C}\right]$ inosine was used to calculate NP activity. One enzyme unit (EU) was defined as the formation of $1 \mu \mathrm{mol}$ uric acid $/ \mathrm{min}$ at $37^{\circ} \mathrm{C}$.

NP purification. NP was purified from hemolysates using biospecific affinity chromatography that involved the coupling of a competitive inhibitor, 6-hydroxy-9-p-aminobenzylpurine, to agarose. ${ }^{3}$ Stroma and hemoglobin were removed from hemolysates as described previously (14), and the resulting hemoglobin free solution passed through a column of affinity gel. After elution of nonspecifically-bound protein, the NP was eluted with a phosphate/inosine solution. The purified enzyme had a specific activity of $120 \mathrm{EU} / \mathrm{mg}$ protein at $37^{\circ} \mathrm{C}$ and after polyacrylamide gel electrophoresis a single band staining for both protein and activity was obtained. This value for specific activity is in agreement with that of a previous purification using conventional column chromatography (3).

Immunological methods. Purified enzyme was used to produce antibodies in rabbits by two footpad and one intravenous injection spaced $1 \mathrm{wk}$ apart. A $2 \mathrm{mg} / \mathrm{ml}$ enzyme solution was mixed with an equal volume of Freund's complete adjuvant, and $1 \mathrm{ml}$ of this mixture was given per injection. The anti-NP immunoglobulins were isolated from the antisera by the method of Harboe and Ingild (15). Ouchterlony immunodiffusion tests were carried out in $0.75 \%$ ionagar; $0.1 \%$ $\mathrm{NaN}_{3}$ at $4^{\circ} \mathrm{C}$ on $3 \times 1$-inch microscope slides, using $2 \mathrm{ml} \mathrm{gel} /$ slide. Immunoelectrophoresis was performed in $1 \%$ agarose in a buffer of pH 8.7 containing $56 \mathrm{mM} 5,5^{\prime}$ diethylbarbituric acid, $31 \mathrm{mM} \mathrm{Na} 5,5^{\prime}$ diethylbarbiturate, $90 \mathrm{mM}$ glycine, $45 \mathrm{mM}$ Tris, on $3 \times 1$-inch microscope slides using $2 \mathrm{ml}$ of gel/slide. The electrode buffer was twice the concentration of the gel buffer, and electrophoresis was at $4^{\circ} \mathrm{C}$ for about 90 min with a voltage of $5 \mathrm{~V} / \mathrm{cm}$, as measured across the gel. After electrophoresis $1-\mathrm{mm}$ channels were cut lengthwise in the gel to receive immunoglobulin. Rocket immunoelectrophoresis (16) was carried out using the agarose gel and buffer conditions described for immunoelectrophoresis. Glass plates $10 \times 10 \mathrm{~cm}$ were coated with $15 \mathrm{ml}$ agarose gel containing $10 \mu \mathrm{l}$ purified immunoglobulin solution. A voltage of $2 \mathrm{~V} / \mathrm{cm}$ was applied across the gel, and $5 \mu \mathrm{l}$ samples were added to 2.5 -mm diameter wells. After $20-30 \mathrm{~h}$ electrophoresis at $4^{\circ} \mathrm{C}$ rocket precipitation outlines were visible in the direction of the anode. The gels were pressed, washed, dried, and stained (17), and the peak heights recorded in millimeters.

${ }^{3}$ Affinity method to be published.
For the reaction of antibody with NP in free solution, 80 $\mu \mathrm{l}$ of sequentially diluted immunoglobulin solutions were added to $30 \mu \mathrm{l}$ of either purified NP or erythrocyte hemolysates. The mixtures were incubated at $37^{\circ} \mathrm{C}$ for $60 \mathrm{~min}$ and then at $4^{\circ} \mathrm{C}$ for $48 \mathrm{~h}$. The precipitated antibody complex was separated by centrifugation and any remaining enzyme activity in the supernatant fluid assayed by the spectrophotometric method.

Nucleoside assay. Purine nucleosides in plasma were determined by high pressure liquid chromatography. Perchloric acid extracts of plasma were prepared by adding $0.1 \mathrm{ml}$ of $20 \%$ cold perchloric acid to $0.2 \mathrm{ml}$ of plasma, and the precipitated protein removed by centrifugation. The supernatant solutions were neutralized by adding two-three drops of $3 \mathrm{M}$ $\mathrm{K}_{2} \mathrm{CO}_{3}$, centrifuged to remove precipitated $\mathrm{KClO}_{4}$, and then adjusted to a total volume of $0.3 \mathrm{ml}$ with water. The treated plasma samples were injected into a Waters $\mu$-Bondapak $C_{18}$ column (Waters Associates, Inc., Milford, Mass.) $(4 \mathrm{~mm} \times 30$ $\mathrm{cm}$ ) equilibrated with $7 \mathrm{mM}$ potassium phosphate buffer, $\mathrm{pH}$ 7.8 , and eluted with a linear gradient of zero to $40 \% \mathrm{vol} / \mathrm{vol}$ methanol in the equilibration buffer, at a flow rate of $2 \mathrm{ml} / \mathrm{min}$. The eluted nucleosides were monitored at $254 \mathrm{~nm}$ by coupling an ultraviolet detector to a strip chart recorder, and the area of each peak was measured by an Autolab IV integrator (Autolab Co., Miami, Fla.). Calibration curves were obtained by using standard nucleoside solutions, and individual peaks were confirmed by co-chromatography with individual standards.

NP denaturation. Pure NP was denatured with $8 \mathrm{M}$ urea at room temperature for $60 \mathrm{~min}$ and then diluted to final concentrations of $1 \mathrm{M}$ urea and $50 \mathrm{mM}$ Na phosphate, $\mathrm{pH}$ 7.4. The resulting solution had no NP activity and showed no colloid or precipitate formation. Control solutions of pure NP in $50 \mathrm{mM} \mathrm{Na}$ phosphate, $\mathrm{pH} 7.4$, with and without $1 \mathrm{M}$ urea were also prepared. The control solutions had the same initial activity and showed negligible loss over a 5-day period. These three solutions were tested by the Ouchterlony diffusion and immunoelectrophoretic methods.

\section{RESULTS}

NP activity. The mean activity of NP in the erythrocytes of 29 controls was $36.5 \pm 4.3 \mathrm{EU} / \mathrm{g} \mathrm{Hb}$ at $37^{\circ} \mathrm{C}$ (range 28.5-43.7). Patient L.M. had no detectable activity even with $2 \mathrm{~h}$ incubation, while her parents had activities of 11.5 and $8.3 \mathrm{EU} / \mathrm{g} \mathrm{Hb} ;-5.7 \mathrm{SD}$ and -6.4 SD below the mean of the controls. These findings are in general agreement with previous reports $(6,7)$. In family B, the patients M.B. and D.B. had activities of 0.2 $\mathrm{EU} / \mathrm{g} \mathrm{Hb}$, representing about $0.5 \%$ of the control mean. Their mother and father had $19.8 \mathrm{EU} / \mathrm{g} \mathrm{Hb}$ and 15.1 $\mathrm{EU} / \mathrm{g} \mathrm{Hb}$, respectively; these values are $-3.7 \mathrm{SD}$ and $-4.8 \mathrm{SD}$ below the control mean.

Plasma nucleoside concentrations. In Table I the concentrations of three nucleosides in plasma are given for the patients, their parents, and 16 controls. Inosine could not be detected in the plasma of normal persons or in the plasma of the parents from either family, whereas in all three patients inosine concentrations greater than $66 \mu \mathrm{M}$ were observed. In one patient (L.M.) an elevation of guanosine concentration was detectable in the plasma. These results are in general agreement with previous reports $(9,18)$. 
Starch gel electrophoresis. A representation of the results from starch gel electrophoresis is shown in Fig. 1. In family $M$ the parents, in comparison with a normal control, exhibit slower moving isozyme bands in their migration patterns. The erythrocytes of their daughter L.M. show no electrophoretic pattern.

Family B shows three different migration patterns. The mother's pattern is similar to a normal control but of reduced activity. The father also has a pattern of reduced activity, but with a predominance of higher activity isozymes migrating towards the anode, whereas the normal pattern displays higher activity isozymes towards the cathode. Their sons' patterns are identical, having a reduced number of isozyme components that are of increased mobility and reduced activity.

Immunodiffusion and immunoelectrophoresis. Fig. 2 shows the reaction in free solution of the purified rabbit immunoglobulin with pure NP. The slope was calculated by standard linear regression analysis and a correlation coefficient of -0.995 was obtained. This plot shows that $1 \mathrm{ml}$ of purified antibody solution neutralizes $115 \mathrm{EU}$ of NP activity. The purified immunoglobulin used was obtained from the pooled antisera from three rabbits. This plot, and similar ones obtained with hemolysates and unpurified rabbit antisera, indicate specific antibody production. This specificity was also shown by immunoelectrophoresis, where a single precipitation arc was obtained with both pure NP and a hemolysate. Also, the eluate collected after passage of hemoglobin-free hemolysate through the affinity column to remove NP gave no reaction when tested by Ouchterlony diffusion or immunoelectrophoresis even after 20 -fold concentration by pressure dialysis.

Fig. 3 shows an Ouchterlony diffusion gel incorporating the hemolysates of patients L.M., D.B. and M.B., their mothers, normal controls, and pure NP. The division into two hemolysate concentrations was necessary because preparations from patient L.M. and her mother were only available at the lower concentration. Patient L.M. displayed no cross-reacting protein, whereas pa-

TABLE I

Purine Nucleoside Concentrations in the Plasma of Family Members and Controls

\begin{tabular}{lrcc}
\hline & Inosine & Adenosine & Guanosine \\
\hline & & $\mu M$ & \\
L. M. & 114.7 & $<1$ & 11.0 \\
D. B. & 70.4 & $<1$ & $<1$ \\
M. B. & 66.5 & $<1$ & $<1$ \\
Parents of families M and B & & & \\
$\quad$ and controls & $<1$ & $<1$ & $<1$ \\
\hline
\end{tabular}

The values for the patients and their parents are the mean of duplicate estimations.

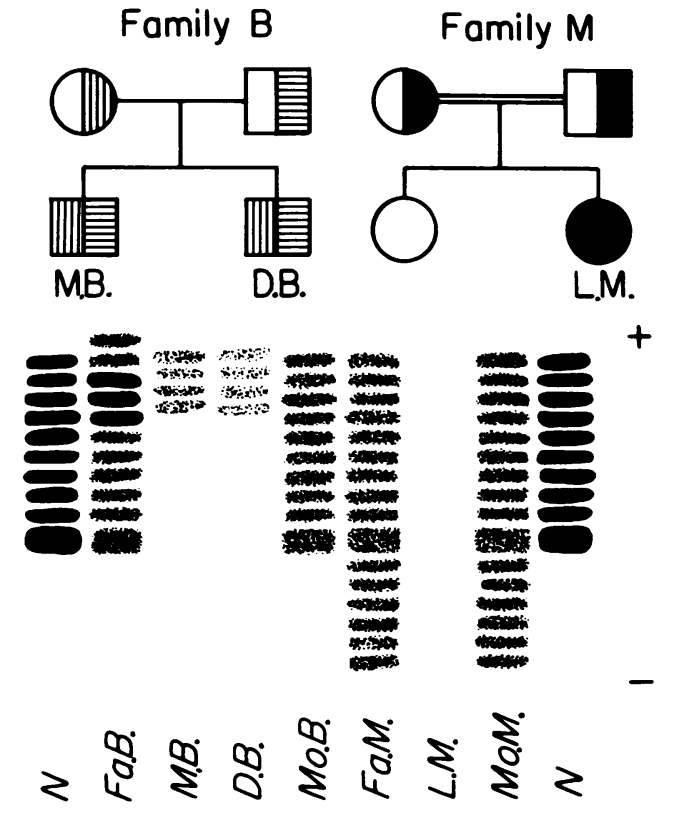

FIGURE 1 Erythrocyte NP starch gel pattern and pedigree of family B and family M. The normal NP gene is indicated by an empty circle or square. In family $\mathbf{M}$, the abnormal allele is shown in black. In family $B$, the two abnormal alleles are indicated by a different cross hatch.

tients D.B. and M.B. and the mothers had precipitin bands that were not distinguishable from the control samples. The absence of a precipitation line with the hemolysate of patient L.M. further confirmed the monospecificity of the antibody preparation.

Fig. 4 shows the results of rocket immunoelectrophoresis as a plot of peak height against enzyme activity. The limit of quantitation by this method is about $3 \%$ of normal immunological-reacting material. The regression analysis of peak height on activity for the 24

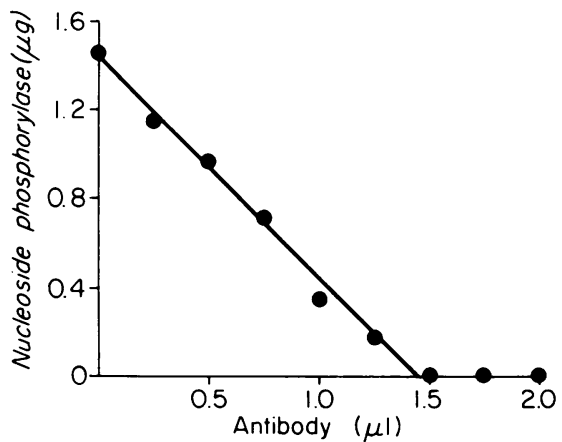

FIGURE 2 Reaction in free solution of pure NP with rabbit anti-NP. Purified antibody, $80 \mu$ l of suitably diluted solution, was reacted with $30 \mu \mathrm{l}$ of $49-\mu \mathrm{g} / \mathrm{ml}$ solution of pure NP. After 60 min at $37^{\circ} \mathrm{C}$ and $48 \mathrm{~h}$ at $4^{\circ} \mathrm{C}$ the precipitated $\mathrm{Ab}$-Ag complex was separated by centrifugation, and any remaining NP activity was determined by the spectrophotometric method.

Purine Nucleoside Phosphorylase Deficiency 


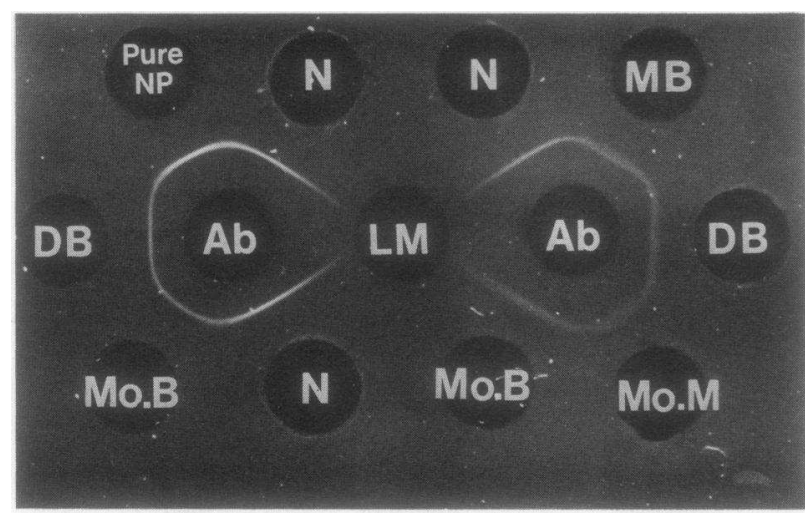

FIGURE 3 Ouchterlony double diffusion gel of erythrocyte hemolysates of the patients, their mothers, and controls of pure NP and normal erythrocyte hemolysate. The family pedigrees are given in Fig. 1 , and $\mathrm{N}$ is the normal control. The hemolysate samples on the left are at concentrations of about $10 \mathrm{~g} \mathrm{Hb} / 100 \mathrm{ml}$; those on the right at about $5 \mathrm{~g} \mathrm{Hb} / 100 \mathrm{ml}$, and the purified NP sample is $49 \mu \mathrm{g} / \mathrm{ml}$.

control samples gave a slope of $0.6500 \pm 0.0088$ (standard error of the slope). The NP activity values of the four parents were used in the regression equation to give peak heights equivalent to their normal (i.e. active) gene product. These values when compared to the observed migration distances, which represent normal plus variant NP protein, enable the amount of variant to be calculated. These values are shown in Table II, with the variant NP expressed as a percentage of the total NP. The observed peak heights and those estimated

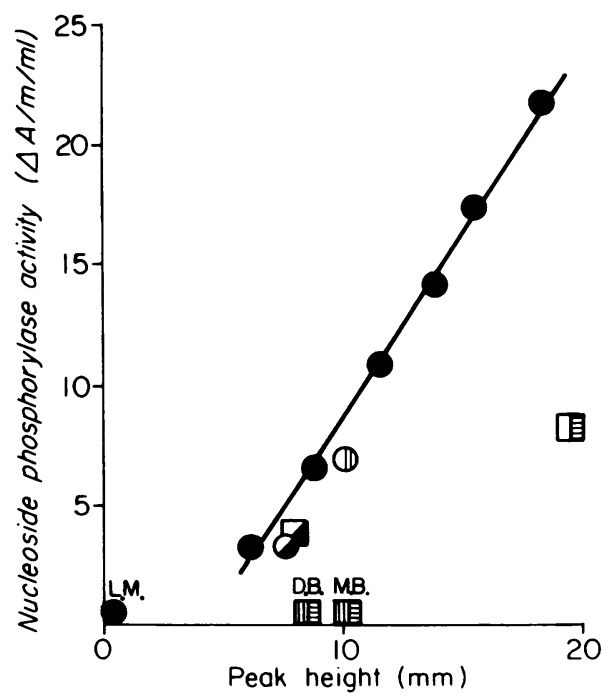

FIGURE 4 Rocket immunoelectrophoresis. Plot of NP activity against migration distance. The values are from two gels run simultaneously that included 24 control samples of suitably diluted erythrocyte hemolysates and duplicates of each family member. The symbols used for the family members are given in Fig. 1. The controls are indicated by black circles.
TABLE II

Proportion of Variant Enzyme in Erythrocytes of the Parents of Families $B$ and $M$

\begin{tabular}{|c|c|c|c|c|}
\hline \multirow{2}{*}{\multicolumn{2}{|c|}{ NP activity }} & \multicolumn{2}{|c|}{ Peak height } & \multirow[b]{2}{*}{$\frac{\text { Variant NP }}{\text { Total NP }}$} \\
\hline & & Observed & $\begin{array}{c}\text { Estimated from } \\
\text { activity }\end{array}$ & \\
\hline \multicolumn{2}{|c|}{$\Delta A_{28 j} / m / m l$} & \multicolumn{2}{|r|}{$m m$} & $\%$ \\
\hline Mo. M. & 3.3 & 7.7 & 6.5 & 15.7 \\
\hline Fa. M. & 3.9 & 7.9 & 6.9 & 12.8 \\
\hline Mo. B. & 7.0 & 10.1 & 8.9 & 11.0 \\
\hline Fa. B. & 8.2 & 19.5 & 9.7 & 50.3 \\
\hline
\end{tabular}

In all cases the estimated peak height due to active enzyme is significantly different from the observed peak height at $P<0.001$.

from the NP activity are significantly different at a probability level of $P<0.001$. As in the Ouchterlony test patients D.B. and M.B. showed immunological-reacting material, whereas patient L.M. did not. However, these immunological techniques cannot be interpreted as positive evidence for the absence of cross-reacting protein in the erythrocytes of L.M., because the enzyme might be denatured and thus unable to diffuse through an agar or agarose polymer. To test for this possibility the urea-denatured pure NP and the two control solutions were subjected to Ouchterlony diffusion and immunoelectrophoresis, and similar results were obtained. The NP treated with $8 \mathrm{M}$ urea showed no precipitation line in either test whereas NP in the presence and absence of $1 \mathrm{M}$ urea gave identical lines. Also, it was shown that in free solution the urea-denatured NP cross reacted with antibody, so the absence of a precipitation line was not caused by lack of antigenicity. This shows that denatured enzyme cannot migrate through agar gel either by diffusion or under the influence of an applied voltage.

\section{DISCUSSION}

The NP deficiencies investigated in this report are not of a common genetic origin. The results indicate the presence of three mutant alleles, one in family $M$ and two in family $B$.

In family $M$ the starch gel and immunoelectrophoresis data suggest the presence of a single variant, and this is supported by the consanguinity of the parents. The inability to demonstrate cross-reacting material in patient L.M.'s erythrocytes by either immunodiffusion or immunoelectrophoresis is very unlikely to reflect a lack of protein synthesis. It is more likely that the variant protein is unstable, especially as a homo-trimer, and denatures rapidly, thus precluding migration through a gel matrix. Denatured NP cannot migrate 
through the gels and this was shown by the experiments with urea-denatured pure NP. That the variant gene synthesizes protein is shown both by rocket immunoelectrophoresis, where the presence of $15.7 \%$ and $12.8 \%$ inactive variant enzyme in the erythrocytes of Mo. M. and Fa. M., respectively, was demonstrated, and by their starch gel patterns which showed the presence of hybrid bands. Also, a decreased rate of variant protein synthesis or increased degradation could contribute to the lower proportion of variant to normal enzyme observed in the parents of this family.

In family $B$ the results indicate the presence of two different variant alleles, neither of which is identical to the variant in family $M$. The variant exhibited by the father is of at least normal stability, as evidenced by rocket immunoelectrophoresis which demonstrated equal quantities of normal and variant enzyme protein. It also has a higher mobility than the normal, as shown by the predominance of activity in the more anodal isozyme bands given by starch gel electrophoresis. The mother of family B displays a normal starch gel isozyme pattern of reduced activity, and a variant protein concentration of about $11 \%$ of her total NP, suggesting an unstable variant as discussed in family $\mathrm{M}$. The probands of this family have about half normal protein, with only a trace of catalytic activity. Their starch gel pattern shows the presence of some hybrid molecules, the majority of which is probably derived from the variant allele of their father.

The interpretation of erythrocyte NP starch gels is somewhat complicated by the secondary isozymes produced during erythrocyte development (19). The normal homozygous trimer should give a single band, and the heterozygote a four-banded pattern, and not the array of bands observed. The most reasonable cause of this multiplicity of bands is the process of deamidation, as shown, for example, by erythrocyte carbonic anhydrase I (20).

The high level of inosine found in the plasma of the three patients is not unexpected, and would be predicted from a deficiency of NP preventing the conversion of inosine to hypoxanthine. It has been postulated that this buildup of inosine causes product inhibition of adenosine deaminase (ADA) (EC 3.5.4.4), the enzyme preceding NP in the reutilization of purines $(21)$. According to this postulate the NP deficiency generates a loss of ADA activity and predicts therefore, that a similar mechanism is responsible for the immune incompetence associated with both NP and ADA deficiency. However, this is probably not the mechanism of immune incompetence in NP deficiency because human erythrocyte ADA does not show any definable product inhibition (22).

It can also be shown that inosine concentrations as high as $2 \mathrm{mM}$ do not have any effect on in vitro lymphocyte stimulation as measured by ${ }^{3} \mathrm{H}$-thymidine in- corporation. ${ }^{4}$ Finally, the two enzyme deficiencies cause classifiably different clinical immune dysfunctions (23). B-cell deficiency, which almost always develops along with the T-cell defect in ADA-deficient children, has not been found in those patients who lack NP.

The two families described in this paper are different in the molecular structure of their deficient enzyme, and in family B in which the parents are unrelated, each has a different mutation. The patients deficient in NP activity have severely impaired T-cell function, and in spite of our knowledge of the enzyme defect we still do not understand the basic mechanism that produces this immune deficiency.

\section{ACKNOWLEDGMENTS}

This work was supported by U.S. Public Health Service grants Al 12617, GM 15253, and HL 17265 and by the National Foundation.

\section{REFERENCES}

1. Kim, K. B., S. Cha, and R. E. Parks. 1968. Purine nucleoside phosphorylase from human erythrocytes. II. Kinetic analysis and substrate binding studies. J. Biol. Chem. 243: 1771-1776.

2. George, D. L., and U. Francke. 1976. Gene dosage effect: regional mapping of human nucleoside phosphorylase on chromosome 14. Science (Wash. D.C.). 194: 851-852.

3. Agarwal, R. P., and R. E. Parks. 1969. Purine nucleoside phosphorylase from human erythrocytes. IV. Crystallization and some properties. J. Biol. Chem. 244: 644-647.

4. Edwards, Y. H., P. A. Edwards, and D. A. Hopkinson. 1973. A trimeric structure for mammalian purine nucleoside phosphorylase. FEBS (Fed. Eur. Biochem. Soc.) Lett. 32: 235-237.

5. Edwards, Y. H., D. A. Hopkinson, and H. Harris. 1971. Inherited variants of human nucleoside phosphorylase. Ann. Hum Genet. 34: 395-408.

6. Giblett, E. R., A. J. Ammann, D. W. Wara, R. Sandman, and L. K. Diamond. 1975. Nucleoside-phosphorylase deficiency in a child with severely defective T-cell immunity and normal B-cell immunity. Lancet. II: 1010-1013.

7. Siegenbeek van Heukelom, L. H., G. E. J. Staal, J. W. Stoop, and B. J. M. Zegers. 1976. An abnormal form of purine nucleoside phosphorylase in a family with a child with severe defective T-cell and normal B-cell immunity. Clin. Chim. Acta. 72: 117-124.

8. Griscelli, C., M. Hauret, and J-J. Ballet. 1976. Third Workshop Int. Coop. Group for Bone Marrow Transplantation in Man. New York.

9. Cohen, A., D. Doyle, D. W. Martin, and A. J. Ammann. 1976. Abnormal purine metabolism and purine overproduction in a patient deficient in purine nucleoside phosphorylase. N. Engl. J. Med. 295: 1449-1454.

10. Scott, C. R., S-H. Chen, and E. R. Giblett. 1974. Detection of the carrier state in combined immunodeficiency disease associated with adenosine deaminase deficiency. J. Clin. Invest. 53: 1194-1196.

11. Beutler, E. 1975. Red cell metabolism: A manual of biochemical methods. Grune \& Stratton, Inc., New York. 11.

${ }^{4}$ To be published. 
12. Kalckar, H. M. 1947. Differential spectrophotometry of purine compounds by means of specific enzymes. 1 . Determination of hydroxypurine compounds. J. Biol. Chem. 167: 429-443.

13. Krenitsky, T. A., G. B. Elion, A. M. Henderson, and G. H. Hitchings. 1968. Inhibition of human purine nucleoside phosphorylase. J. Biol. Chem. 243: 2876-2881.

14. Osborne, W. R. A., and N. Spencer. 1973. Partial purification and properties of the common inherited forms of adenosine deaminase from human erythrocytes. Biochem. J. 133: 117-123.

15. Harboe, N., and A. Ingild. 1973. Immunization, isolation of immunoglobulins, estimation of antibody titre. Scand. J. Immunol. 2 (Suppl. 1): 161-164.

16. Weeke, B. 1973. Rocket immunoelectrophoresis. Scand.J. Immunol. 2 (Suppl. 1): 37-46.

17. Weeke, B. 1973. General remarks on principles, equipment, reagents and procedures. Scand. J. Immunol. 2 (Suppl. 1): 15-35.

18. Stoop, J. W., B. J. M. Zegers, G. F. M. Hendrickx, L. H. Siegenbeek van Heukelom, G. E. J. Staal, P. K. de Bree,
S. K. Wadman, and R. E. Ballieux. 1977. Purine nucleoside phosphorylase deficiency associated with selective cellular immunodeficiency. N. Engl. J. Med. 296: 651655.

19. Turner, B. M., R. A. Fisher, and H. Harris. 1971. An association between the kinetic and electrophoretic properties of human purine-nucleoside-phosphorylase isozymes. Eur. J. Biochem. 24: 288-295.

20. Funakoshi, S., and H. F. Deutsch. 1969. Some physiochemical properties of native isozymes and of similar isozymes generated in vitro. J. Biol. Chem. 244: 3438-3446.

21. Ullman, B., A. Cohen, and D. W. Martin. 1976. Characterization of a cell culture model for the study of adenosine deaminase and purine nucleoside phosphorylase-deficient immunologic disease. Cell. 9: 205-211.

22. Osborne, W. R. A. 1972. The biochemistry of inherited forms of human red cell adenosine deaminase. Ph.D. Thesis. University of London.

23. Giblett, E. R. 1976. Immune cell function and recycling of purines. N. Engl. J. Med. 295: 1375-1376. 